\title{
CONSTRUIRE SES CAPTEURS MÉTÉO
}

\author{
Guy Isabel
}

L'auteur présente dans ce livre quelques « capteurs » météorologiques de base qui peuvent être réalisés et utilisés par un amateur.

Outre quelques définitions de paramètres météorologiques (tels que la pression atmosphérique, la température de l'air, etc.) et des informations annexes

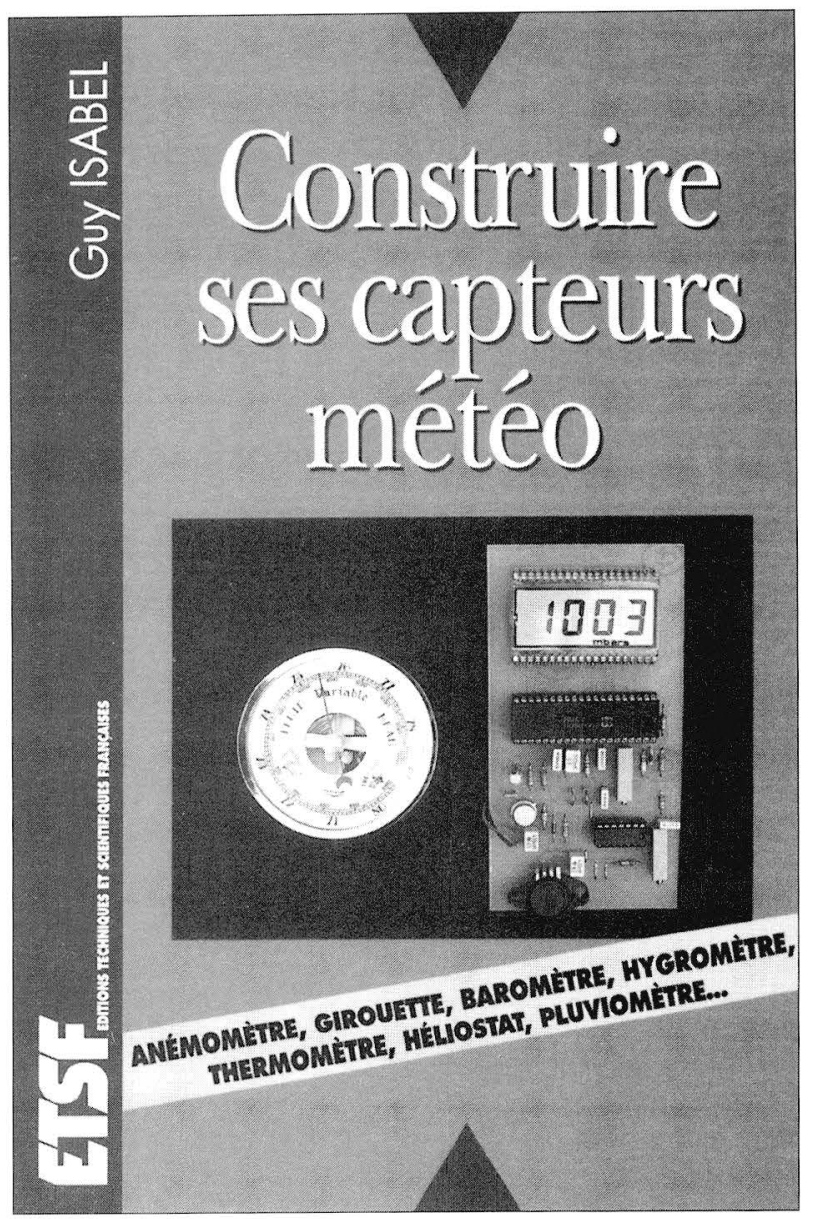
le secteur et une horloge digitale.

Outre leur simplicité, notons que les systèmes présentés seront peu onéreux à réaliser. Par ailleurs, l'auteur donne quelques informations sur certains kits disponibles dans le commerce et les adresses de sociétés susceptibles de fournir des matériels toujours destinés aux amateurs, mais plus élaborés du point de vue technique (utilisant notamment des micro-ordinateurs). 
Le reproche que l'on pourrait formuler à ce document est de ne pas présenter la partie mécanique des capteurs (cela est particulièrement pénalisant dans le cas de la girouette et de l'anémomètre) et d'être assez discret sur leurs méthodes d'étalonnage. Il faut cependant reconnaître la difficulté d'une telle démarche.

En conclusion, voilà une excellente introduction aux différents types d'électroniques de mesure qui devrait séduire les météorologistes amateurs.

Pierre Grégoire

Construire ses capteurs météo.

Par Guy Isabel.

Éditions techniques et scientifiques françaises, Paris, 1994, 108 p. 